Marquette University

e-Publications@Marquette

College of Education Faculty Research and

Publications

Education, College of

$1-1-2014$

\title{
Treatment Outcomes for At-Risk Young Children With Behavior Problems: Toward a New Definition of Success
}

\author{
Michael P. Fung \\ Marquette University \\ Robert A. Fox \\ Marquette University, robert.fox@marquette.edu \\ Sara E. Harris \\ Marquette University
}

Accepted version. Journal of Social Service Research, Vol. 40, No. 5 (2014): 623-641. DOI. (C 2014 Taylor \& Francis (Routledge). Used with permission. 


\title{
Treatment Outcomes for At-Risk Young Children With Behavior Problems: Toward a New Definition of Success
}

\author{
Michael P. Fung \\ Department of Counselor Education and Counseling Psychology, \\ College of Education, Marquette University \\ Milwaukee, WI \\ Robert A. Fox \\ Department of Counselor Education and Counseling Psychology, \\ College of Education, Marquette University \\ Milwaukee, WI \\ Sara E. Harris \\ Department of Counselor Education and Counseling Psychology, \\ College of Education, Marquette University \\ Milwaukee, WI
}

This research was supported in part by grants from Brighter Futures of Milwaukee, Charles D. Jacobus Family Foundation, Exchange Clubs of Greater Milwaukee Charitable Foundation, Faye McBeath Foundation, Helen Bader Foundation, and United Way. The authors acknowledge the support of Penfield Children's Center, a Birth-to-Three Agency that served as the site for this study, as well as the family clinicians and graduate students who provided mental health services for the children and their families. 
NOT THE PUBLISHED VERSION; this is the author's final, peer-reviewed manuscript. The published version may be accessed by following the link in the citation at the bottom of the page.

Correspondence concerning this article should be addressed to Robert A. Fox, Ph.D., Marquette University, Department of Counselor Education and Counseling Psychology, College of Education, 168D Schroeder Complex, P. O. Box 1881, Milwaukee WI 53201-1881. E-mail: robert.fox@marquette.edu; Phone: 414-288-1469.

\section{Abstract:}

This study examined the effects of an in-home Parent-Child Therapy (PCT) program with 447 at-risk children under the age of five who were referred for severe behavior and emotional problems, such as aggression, oppositional behavior, and separation anxiety. Outcomes were assessed using a unique two-dimensional definition of treatment completion, which consisted of treatment duration and an assessment of reliable change for the primary outcome measure of child behavior problems. Results showed that the majority of children (63.4\%) met or exceeded treatment completion. Findings offered support for the use of this two-dimensional definition to assess successful treatment completion in PCT programs. In addition, repeated measures, multivariate analysis of variance revealed increased child pro-social behaviors, increased caregiver nurturing, an increase in developmentally-appropriate expectations of children, improved parent-child relationships, and a decrease in clinical diagnoses following treatment. The clinical and research implications of this new definition of treatment completion, as well as future directions for PCT programs, are discussed.

Keywords: Behavior problems, at-risk, young children, treatment.

Behavior problems (e.g., aggression, oppositional behavior, separation anxiety) in young children ages five and under are common (Fox \& Holtz, 2009), and often begin in the toddler and preschool years (Keenan \& Wakschlag, 2000). For most children, these behaviors are a typical part of development and fade over time. However, $10-15 \%$ of these children develop moderate behavior problems, $50 \%$ of which experience a persistent escalation in severity by elementary school (Campbell, 1995; Shaw, Lacourse, \& Nagin, 2005). Without intervention, these behavior problems often develop into more severe psychiatric symptoms as children progress into adolescence and adulthood (Campbell, 2002). Research has shown that behavior problems in young children can negatively impact child social interactions (Mendez, Fantuzzo, \& Cicchetti, 2002), damage parent-child relationships (Greene \& Doyle, 1999), hamper school readiness (Bulotsky-Shearer, Dominguez, \& Bell, 2012), and increase 
the risk for abuse and neglect (Francis \& Wolfe, 2008). Further, these behavior problems are associated with higher expulsion rates from early childhood programs, hindering long-term educational achievement (Breitenstein et al., 2007). This negative trajectory of behavior problems in young children highlights a significant need for effective Parent-Child Therapy (PCT) programs that promote healthy psychosocial development in children under the age of five (Keenan, Shaw, Delliquadri, Giovannelli, \& Walsh, 2000).

The current literature has identified several factors that are potentially associated with the development of child behavior problems, including verbal and corporal punishment (Brenner \& Fox, 1998; Nicholson, Fox, \& Johnson, 2005), lower socioeconomic status (SES) and lower maternal education level (Fox, Platz, \& Bentley, 1995), single motherhood (Fox et al., 1995), genetic predisposition (Moffitt, 2005), hostile attribution bias (Snarr, Smith Slep, \& Grande, 2009), parental anger (Ateah \& Durrant, 2005; Francis \& Wolfe, 2008), and general life stress (Abidin, Jenkins, \& McGaughey, 1992; Kazdin \& Whitley, 2003). Often, there is a complex developmental and maintenance cycle of child behavior problems in which aggressive parental exchanges through verbal and corporal punishment may unwittingly reinforce child misbehavior (Patterson, Reid, \& Dishion, 1992; Sanders, Dadds, \& Bor, 1989). As parents exhibit parental aggression in response to child misbehavior, a self-perpetuating cycle may develop where the frustrated child reciprocates with aggression (Patterson \& Forgatch, 1990; Sanders, Dadds, Johnston, \& Cash, 1992). Said differently, parental aggression (e.g., frustration, anger, corporal punishment) may teach the child to model this behavior and respond with aggression when they experience distress. As a result, the development of child behavior problems is a complicated relationship between parental cognitions, practices, and emotional reactivity and child misbehavior (Patterson \& Forgatch, 1990; Strassberg, 1995). These behavior problems can engender future cycles of violence and abuse, negatively impacting these children's long-term outcomes (Einfeld et al., 2006; Roberts, Mazzucchelli, Studman, \& Sanders, 2006). It is therefore necessary for PCT programs to address a myriad of issues to target these components when working with families whose children are referred for behavior problems. 
In the past two decades, several PCT programs have been developed, such as Parenting Young Children (PYC; Fox, 2013), Parent Child Interaction Therapy (PCIT; Eyberg \& Boggs, 1989), Incredible Years Parenting Program (IYP; Webster-Stratton, 1992), and Triple-P Positive Parenting (Triple P; Sanders, 1999). Research on PCIT, IYP, and Triple $P$ has shown successful outcomes for children with behavior problems (Eyberg et al., 2001; Roberts et al., 2006; Webster-Stratton, Reid, \& Hammond, 2004). Despite this success, the majority of these interventions for children ages five and under is not specifically tailored for low-income families (Coard, Wallace, Stevenson, \& Brotman, 2004). This is particularly concerning considering that atrisk children living in poverty have a significantly greater risk for poorer social and emotional outcomes (Ackerman, Brown, \& Izard, 2003; Youngstrom, Weist, \& Albus, 2003). Research has found that up to $36 \%$ of preschool children from low-income families exhibit behavior problems (Anthony, Anthony, Morrel, \& Acosta, 2005; Qi \& Kaiser, 2003). These negative outcomes are due, in part, to a lack of availability and accessibility to mental health services (Spencer, Kohn, \& Woods, 2002). Research also has shown that families with low socioeconomic status (SES) often drop out of PCT treatment due to contextual factors, such as loss of phone services, child illnesses, and financial and family crises, as well as frequent relocation (Nicholson et al., 1999).

In response to these challenges, there has been a gradual increased emphasis on providing treatment for at-risk children living in poverty. Reid, Webster-Stratton, and Baydar (2004) reported significant improvement in child behavior problems in a sample of 882 children from Head Start programs. Fernandez, Butler, and Eyberg (2011) conducted a pilot study of PCIT with African American children from low-income families and found successful outcomes for children who completed treatment. Concurrently, there has been a recent trend to offer school-based services in an attempt to decrease the contextual barriers for at-risk children. For example, WebsterStratton, Reid, and Stoolmiller (2008) provided group PCT services to parents of children from low-income families who were enrolled in Head Start, kindergarten, and first-grade programs; improved child behavior was reported. Brotman et al. (2011) also examined a schoolbased group PCT program for children in prekindergarten from lowincome families and reported a significant decrease in behavior 
problems. In addition, Breitenstein et al. (2007) reported positive outcomes for a group PCT program that was adapted for at-risk African American Head Start students. Similarly, Gross et al. (2009) reported improvements in child behavior following a group PCT program for atrisk Latino children in day care centers. These efforts reflect the growing realization that at-risk children require services tailored to their specific needs, which requires innovative intervention methods. Despite their success, each of these programs offered treatment in community organizations or schools, which may not be the ideal settings for low-income families considering the contextual factors (e.g., transportation, maintaining clinic appointments) that may prevent families from attending treatment. As an alternative treatment setting, Wood, Barton, and Schroeder (1988) pointed out that in-home therapy has several major advantages including the ability to better tailor services to fit the unique needs of each family, an opportunity to obtain rich information on family dynamics and behaviors of individual members as they naturally occur, and the ability to provide services to individuals who would otherwise be unable to attend sessions at a clinic or school. Fox and Holtz (2009) also noted that in-home therapy was particularly efficacious for children with behavioral concerns as the behaviors could be addressed and corrected as they naturally occurred in session. In fact, in-home therapy was just as effective as residential care for behaviorally troubled children and is recommended as a preferred modality due to reductions in restrictiveness and cost (Barth et al., 2007).

The PYC program uniquely offers in-home parent-child therapy for young children, which focuses on parent-directed training and child behavior activities to decrease child behavior problems. Multiple studies have reported the efficacy of the PYC model for young children with behavior problems, notably including at-risk children living in poverty (Fox \& Holtz, 2009; Nicholson, Anderson, Fox, \& Brenner, 2002), children with developmental delays (Holtz, Carrasco, Mattek, \& Fox, 2009) and children from different ethnic backgrounds (Gresl, Fox, \& Fleischmann, in press). In addition, a mental health clinic providing in-home PCT services to at-risk children with developmental delays and severe behavior problems has reported successful treatment outcomes for the past decade (Fox, Keller, Grede, \& Bartosz, 2007). 
Despite the gradual movement to provide treatment for at-risk young children, several issues still exist that have not been addressed sufficiently in the literature. One of the most significant and immediate concerns is addressing how treatment completion is defined. Variability in the operationalization of treatment completion can lead to conflicting results and an inability to replicate research (Kazdin \& Mazurick, 1994). Definitions of treatment completion in the field of mental health have included treatment duration (Swift, Callahan, \& Levine, 2009), failure to attend the final treatment session (Hatchett \& Park, 2003), failure to return after intake (Longo, Lent, \& Brown, 1992), therapist judgment (Hatchett \& Park, 2003), and clinically significant and reliable change criteria (Hatchett \& Park, 2003). This poses a significant problem in effectively evaluating change across programs.

Central to this argument is how to operationalize treatment completion in a way that considers current research, demographic and contextual variables of the target sample, and provides adequate detail for replication and comparison across studies. Support for a duration component of treatment completion comes from the doseeffect literature, which has suggested that participant outcomes are positively correlated with the number of sessions attended (Barkham et al., 2006). However, Barkham et al. (2006) also found that the percentage of clients improving in therapy generally did not change or even declined with the number of sessions and suggested that clients may discontinue services before formal termination once they reach a level of satisfactory gain. In other words, this suggests that arbitrarily using completion of post-test session may not capture clients who made significant change but chose to discontinue services after the change was obtained. Additionally, demographic variables that impact treatment completion must be considered. A meta analysis of 125 studies of psychotherapy dropout found significant effect sizes (.23.37) for education level, racial status and income, with less educated, minority, lower income groups dropping out before treatment completion (Wierzbicki \& Pekarik, 1993). As mentioned, families with low socioeconomic status (SES) often drop out of PCT treatment due to several contextual factors (Nicholson et al., 1999). As a result, many families who may be successful in treatment are lost to attrition because they lack a formal post-test. A primary drawback of using duration as the sole criterion of successful treatment completion is that 
some clients do not improve after a significant number of sessions while others demonstrate significant change after relatively few sessions (Barkham et al., 2006). Thus, a reliable change index (RCI; Jacobson \& Truax, 1991) of the primary outcome measure has been recommended to supplement the duration component (Swift et al., 2009). This involves administering the primary outcome measure at each treatment session in order to obtain comparison data. This method offers a logically valid and highly reliable measure of client improvement during treatment (Swift et al., 2009). By combining these two components, namely, a minimum length of treatment combined with a reliable change index, PCT programs can measure both participation in treatment and reduction in child behavior problems, moving toward what Swift et al. (2009) suggested, a multimethod approach to determine treatment completion that incorporates several dimensions of treatment and addresses the inherent flaws of each individual definition (Hatchett \& Park, 2003; Swift et al., 2009).

In the current PCT literature, the IYP program defined treatment completion as attendance to seven or more treatment sessions (Lavigne et al., 2010) while both the PYC and the Triple-P program used completion of formal post-test measures as their definition of treatment completion (de Graaf et al., 2008; Carrasco \& Fox, 2012). The fourth program, PCIT, required three criteria for treatment completion: (a) the child participant must score below a cutoff on a self-report measure of child behavior problems, (b) the caregiver and clinician must agree that the caregiver is prepared to independently manage the child's behavior, and (c) the caregiver must meet a specified level of mastery for program activities (Lyon \& Budd, 2010). As a result of these differing definitions, reports of child and family attrition percentages are highly variable. For example, attrition rates vary from as low as $10 \%$ (Nicholson et al., 2002) to as high as over 70\% (Carrasco \& Fox, 2012; Chaffin et al., 2009). At other times attrition rates are not even reported. The PCIT program comes closest to using a multi-dimensional definition. However, it focuses primarily on outcome measures and clinician judgment without including a treatment duration component. In addition, PCIT sessions are most commonly conducted with Caucasian families in controlled clinical settings (e.g., academic labs) or social service settings (e.g., primary care clinics, community organizations) rather than in the homes of traditionally underserved, at-risk families. 
NOT THE PUBLISHED VERSION; this is the author's final, peer-reviewed manuscript. The published version may be accessed by following the link in the citation at the bottom of the page.

The primary purpose of the present study was to begin the process of developing and analyzing a new, two-dimensional definition of successful treatment completion for an adapted-PYC model. The two dimensions of successful treatment completion included attendance at a comprehensive intake session and three or more treatment sessions and meeting the criterion for a reliable change index (RCI; Jacobson \& Truax, 1991) on the primary outcome measure of child behavior problems. Three sessions was determined to be the ideal duration cutoff because critical treatment strategies were frontloaded into the first three sessions to provide a significant amount of information early in treatment. In addition, typical dropout for the PYC program has occurred around the fourth session (Fox \& Holtz, 2009). The second purpose of this study was to provide additional evidence for previously reported successful outcomes of the PYC program delivered in the homes of young children living in poverty.

Given these purposes, this study attempted to answer the following research questions:

1. Did a new two-dimensional definition of treatment completion offer an effective way of identifying successful treatment completion of the PYC program?

2. Did children referred for mental health services decrease the frequency and severity of their challenging behaviors based on the Early Childhood Behavior Screen-Challenging Behavior Scale (ECBS-CBS; Holtz \& Fox, 2012) and improve their pro-social behaviors based on the ECBS-Positive Behavior Scale (ECBSPBS; Holtz \& Fox, 2012) following their participation in this PYC program? Were these changes maintained at four-six week follow-up?

3. Did children improve their relationship with their primary caregiver based on direct observation of parent-child interactions using the Parent-Child Play Assessment (PCPA) following their participation in this PYC program? Were these changes maintained at four-six-week follow-up?

4. Did parents and other primary caregivers (e.g., foster parents, grandparents) improve their parenting skills based on the Discipline and Nurturing scales of the Parent Behavior Checklist 
(PBC; Fox, 1994) following their participation in this PYC program? Are these changes maintained at four-six-week follow-up?

5. Did parents and other primary caregivers (e.g., foster parents, grandparents) exhibit more developmentally appropriate expectations of their children based on the Expectations scale of the PBC following their participation in this PYC program? Were these changes maintained at four-six-week follow-up?

6. Did children lose their psychiatric diagnoses based on the Diagnostic and Statistical Manual of Mental Disorders (DSM; APA, 2000) psychiatric criteria following their participation in this PYC program? Were these changes maintained at four-sixweek follow-up?

7. Did children improve their interactions with their primary caregiver based on the Parent-Child Relationship Scale (PCRS) and improve their general functioning based on the Global Assessment of Functioning (GAF) following their participation in this PYC program? Were these changes maintained at four-sixweek follow-up?

8. Were families satisfied with the services based on the Family Satisfaction Scale (FSS) following their participation in this PYC program?

\section{Method}

\section{Participants}

The setting for this study was a mental health clinic that specialized in providing in-home mental health services for children five years of age and younger (Fox et al., 2007). The clinic was housed within a non-profit Birth-to-Three organization located within a large urban community in the Midwest. Participants were at-risk children five years of age or younger who were referred for severe behavior and emotional problems (e.g., aggression, oppositional behavior, separation anxiety) by over 50 community-based agencies in 
addition to individual providers (e.g., pediatricians, public health nurses), parents, and other family members (e.g., grandmothers). All referred children who met the study's eligibility criteria were accepted for the study. Eligibility criteria for this study included: (a) the child was under 72 months of age; (b) the child was referred for a significant mental health concern such as aggression, destructiveness, hyperactivity, self-injury, and separation anxiety; (c) the child did not have a serious physical disability, health concern, or meet the criteria for moderate to profound mental retardation or autistic spectrum disorder; however the child may have had a developmental delay; (e) the family met the federal criteria for living in poverty (e.g., eligible for public assistance programs); (f) the primary caregiver signed an IRBapproved informed consent form for the child and family to participate in this study.

Four hundred and forty seven families participated in this PYC program, which provided in-home therapy to help families effectively address their child's referral concerns. Caregivers were primarily mothers (89.3\%). Average primary caretaker age was 29.7 years (SD $=8.27)$; average child age was $3.16(S D=1.05)$. There were 300 boys $(67.1 \%)$ and 147 girls (32.9\%); the majority of the children were African American (52.8\%), 19.9\% were Latino, 11\% were Caucasian, and $16.4 \%$ reported multiracial origins. The majority of families were receiving public assistance $(89.6 \%)$, which required that they met the federal definition of poverty. Additionally, $61.5 \%$ of primary caregivers indicated that they were unemployed. Fifty-one percent of children were diagnosed with a developmental delay, of which $90 \%$ were language delays. During pregnancy, $14.8 \%$ of caregivers reported drug or alcohol use and $35.6 \%$ reported complications during pregnancy or delivery. Approximately half (50.1\%) of the children also had significant health concerns (e.g., asthma, ear infections, seizures, high lead level). At intake, $96.4 \%$ of children received an initial psychiatric diagnosis. Oppositional Defiant Disorder was the most common primary diagnosis at intake (48.8\%); additional primary diagnoses included other (24.3\%; e.g., Disruptive Behavior Disorder NOS), Adjustment Disorder (10.4\%), Attention Deficit Hyperactivity Disorder (5.2\%), Parent-Child Relationship Problem (2.8\%), Separation Anxiety (2.6\%), Post-Traumatic Stress Disorder (2.4\%), Pervasive Developmental Disorder (1.9\%), Reactive Attachment 
Disorder $(.9 \%)$, and Conduct Disorder (.7\%). In addition, $31.6 \%$ also received secondary psychiatric diagnoses at intake.

\section{Procedure}

This project was approved by the Internal Review Board of Marquette University. As noted, participants were referred from over 50 community-based agencies, individual providers (e.g., pediatricians, public health nurses), and parents themselves. Over the past decade in this large urban community, the PYC program has built a reputation as a primary treatment provider for young children with severe behavior and emotional problems as well as established longstanding relationships with community-based agencies and individuals. Therefore, while no formal recruiting procedures were conducted for this project, ongoing outreach to community constituents was completed, including presentations and trainings about this adapted-PYC program and its benefits. Project data were collected in participants' homes as part of the in-home treatment program, which occurred over a two-year period from 2010 to 2012. All participants signed an informed consent form describing the purpose, risks, and benefits of treatment prior to completing the intake evaluation. Caregivers also were asked to sign a contract agreeing to actively participate in treatment. This included being present with their child at all sessions, actively implementing treatment strategies in and out of treatment sessions, and providing 24 hours' notice for session cancellations.

Parent-Child Therapy. This PCT program was adapted from the evidence-based PYC program (Fox, 2013). Key treatment components were maintained across families with minor adaptations in content to tailor the information and strategies to each family's unique situation (e.g., clarification of details, order of activities, pace information was presented). Intake duration was approximately 90-120 minutes and treatment sessions typically lasted 60-90 minutes.

During early stages of treatment, caregivers were taught childled play, a non-directive interaction that allows the child to choose and lead play while the caregiver follows along and offers positive comments on child activities. The goal was to strengthen the parentchild relationship, and caregivers were encouraged to participate in this play at least 15 minutes each day outside of the treatment 
sessions. The rationale for this activity was two-fold: (a) the quality of the parent-child relationship had often deteriorated as a result of the child's behavior challenges, and (b) strengthening the parent-child relationship provided a foundation for effective implementation of subsequent cognitive and behavioral strategies. There were five additional components to the PCT program. First, psychoeducation regarding child development and reasonable parent expectations as well as information about the development and maintenance of challenging behaviors was offered to caregivers. That is, the distinction between child behavior and child personality was explained in order to emphasize to caregivers that the child's challenging behaviors were the problem rather than the child. Second, caregivers were taught the STAR technique (Fox \& Fox, 1992), a cognitivebehavioral strategy to manage responses to challenging behavior in a more reasonable and thoughtful manner. Caregivers were instructed to stop (S) before reacting to their child's challenging behaviors, think ( $T$ ) about their thoughts and emotions, ask (A) themselves what a developmentally appropriate response would be, and finally respond (R) to the child. Third, appropriate developmental expectations based on the child's developmental age were discussed with caregivers. Fourth, caregivers were taught to effectively implement behavioral strategies, such as positive reinforcement and structured routines, in order to increase children's pro-social behaviors. Finally, strategies to manage challenging behaviors were introduced, including ignoring, redirection, limit setting, natural consequences, and time-outs; all forms of verbal and corporal punishment were strongly discouraged. Clinicians provided caregivers with behavior treatment plans with activities and a daily checklist to facilitate caregiver practice each week, which families completed and returned at the beginning of the subsequent session.

Clinician Training. Clinicians included two full-time licensed professional counselors, one clinical social worker, one part-time licensed professional counselor, one part-time counselor-in-training, three doctoral psychology students, and five master's level graduate students who were completing practicum or internship placements. A consulting psychologist and clinical social work director provided supervision while senior clinicians and doctoral students trained novice clinicians on the treatment protocol using a three-step process: (a) novice clinicians received didactic training on the PCT program, (b) 
they shadowed senior clinicians on in-home visits, and (c) they gradually implemented components of in-home treatment protocol under supervision until they demonstrated mastery. Additionally, incoming clinicians were trained on how to competently interact with a diverse racial and ethnic population within an urban setting, from lowincome backgrounds. When novice clinicians effectively maintained treatment integrity, used appropriate professional demeanor, showed cultural sensitivity, and completed administrative documentation based on a treatment integrity checklist completed by their supervisors, they were allowed to facilitate individual cases. Each unlicensed clinician received weekly individual supervision to receive feedback on their performance and attended weekly group case management meetings to discuss client progress, address potential concerns, and obtain new ideas for working with a particular family.

\section{Research Design}

A convenience sample of all consecutive children who met the study's criteria and were referred to the PYC program was used. Children were entered into the database in the order that they were referred and found eligible to participate in the study. A pre-, post-, follow-up within-subjects experimental design was used. Participants completed an intake session, six to eight treatment sessions, a post-test session, and a four-six week follow-up session. Average program duration was 2.47 months $(S D=1.39)$. Booster sessions were provided at the request of families after the follow-up session.

\section{Measures}

Intake Form (IF). At the first meeting with the family in the child's home, the IF was used to collect demographic information about the referred child (e.g., gender, date of birth, siblings), and the family and others who were living in the child's home and/or providing care for the referred child (e.g., grandmother, aunt, preschool, day care center). The IF also was used to collect information about the child's birth history, current health, previous involvement with child protective services, and medications, if any. In addition, the IF helped determine the frequency and nature of the child's referral concerns, possible contributing factors, and how the caregivers were presently responding to the referral concerns. The IF was updated regularly as 
new information became available (e.g., family moved to new address, parents separated).

Early Childhood Behavior Screen (ECBS). The ECBS (Holtz \& Fox, 2012 ) is a 20-item self-report screening instrument developed specifically for very young children ( 0 to five-years-old) from low-SES backgrounds. The ECBS was administered at pre-test, all individual treatment sessions, post-test, and follow-up. The ECBS includes 10 positive behavior items (e.g., "listens to you," "shares toys") and 10 challenging behavior items (e.g., "hits others," "has temper tantrums") and is written at a 3.9 grade level. The scale instructions ask caregivers to rate each item based on their perception of their child's behavior over the past week using a three-point Likert rating scale (1 = almost never, 2 = sometimes, $3=$ often). Total scores on the Positive Behavior Scale (PBS) range from 10 to 30 with higher scores indicating a greater frequency of pro-social behaviors. Total scores on the Challenging Behavior Scale (CBS) range from 10 to 30 with higher scores indicating a greater frequency of challenging behaviors. Fieldtesting of the ECBS was conducted with a representative, diverse sample of 439 parents from a low-SES urban community. Internal consistencies using coefficient alphas were reported for the CBS (.87) and PBS (.92). The CBS demonstrated adequate levels of concurrent validity $(r=.75)$ with the Eyberg Child Behavior Inventory (ECBI; Eyberg \& Pincus, 1999). In addition, the CBS demonstrated adequate levels of sensitivity ( $82 \%)$ and specificity $(80 \%)$ based on its relationship with the ECBI.

Parent Behavior Checklist (PBC). The PBC (Fox, 1994) is a 32-item rating scale that is designed to measure the behaviors and expectations of parents of young children between the ages of one and five. The PBC was administered at pre-test, post-test, and follow-up. For this project, all three subscales were used from the PBC. The discipline subscale consisted of 10 items that assessed parental response to the child's problem behaviors (e.g., "I yell at my child for whining"). The nurturing subscale consisted of 10 items that measured specific parent behaviors that promoted the child's psychological growth (e.g., "My child and I play together on the floor"). The expectation subscale consisted of 12 items that measured specific parent expectations of the child's behaviors (e.g., "My child should be able to ride a tricycle"). Items were rated using a four-point

Journal of Social Service Research, Vol. 40, No. 5 (2014): pg. 623-641. DOI. This article is (c) Taylor \& Francis (Routledge) and permission has been granted for this version to appear in e-Publications@Marquette. Taylor \& Francis (Routledge) does not grant permission for this article to be further copied/distributed or hosted elsewhere without the express permission from Taylor \& Francis (Routledge). 
frequency scale $(1=$ almost never/never, 2 = sometimes, $3=$ frequently, and $4=$ almost always/always). Total scores for discipline ranged from $10-40$, with higher scores indicating more frequent use of verbal and corporal punishment (e.g., yelling, spanking). Total scores for nurturing ranged from $10-40$, with higher scores suggesting more frequent use of positive nurturing activities (e.g., reading with child, playing with child). Total scores for expectations ranged $=12-48$, with higher scores suggesting greater expectations of child behaviors compared to the child's developmental level (e.g., expecting a two-year-old child to dress himself/herself). From a representative sample of 1,140 mothers, the following internal consistencies using coefficient alphas were reported: Discipline $=.91$, Nurturing $=.82$, and Expectations $=.97$. Test-retest reliabilities for each of the three subscales were: Discipline $=.87$, Nurturing $=.81$, and Expectations $=.98$.

Parent-Child Play Assessment (PCPA). Parents were instructed to play with their child with toys they had in the home while the counselor observed and rated the quality of the parent-child interaction. If no toys were available, the counselor provided them. Based on the work of Crawley and Spiker (1983), four dimensions of the child's behavior were rated using a five-point Likert-type scale ( 1 $=$ never, $2=$ seldom, 3 = average, $4=$ usually, $5=$ always). For 36 observations of the parent-child interactions, two counselors independently completed the play assessment. Kappa coefficients were computed for child behaviors that included positive affect $=.80$, negative affect $=.81$, interest in play $=.47$, and initiates interactions $=.61$. The size of these coefficients indicated moderate to good agreement between observers (Viera \& Garrett, 2005). A total score was computed for the four dimensions of the child's behaviors. Scores ranged from 4 to 20 with higher scores representing more positive child interactions during play. The coefficient alpha for the sample was (.78).

Diagnostic and Statistical Manual of Mental Disorders (DSM; APA, 2000). Children who met the criteria for one or more primary diagnoses at intake (Axis I) had this information added to their intake report. In addition, the other four Axes of the DSM were completed for each child, including the Global Assessment of Functioning (GAF). For this study, the GAF score was completed at pre-test, post-test, and 
follow-up. When two counselors were present, each completed an individual GAF score. Based on 45 cases, the kappa coefficient for inter-rater reliability was .52. This indicates moderate agreement between observers (Viera \& Garrett, 2005).

Parent-Child Relationship Scale (PCRS). This scale provided a subjective, quantitative global assessment of the parent-child relationship on a scale of 0-100 with five behavioral anchors (poor, below average, average, good, and exceptional) at 20-point intervals (Fox \& Nicholson, 2003). For example, scores suggestive of a good relationship (e.g., thoughtful interactions, typically appropriate parental expectations, parent responsiveness, appropriate limit setting, and limited use of verbal or corporal punishment) ranged from 60-80. For the study, the PCRS score was completed at pre-test, post-test, and follow-up. When two counselors were present, each completed an individual PCRS global score. Based on 42 cases, the kappa coefficient for inter-rater reliability was .51. This indicates moderate agreement between observers (Viera \& Garrett, 2005).

Family Satisfaction Survey. At the completion of the treatment program, a 7-item anonymous survey was used to assess caregiver satisfaction with the treatment services. On a 7-point Likert rating scale, caregivers were asked to rate: the quality of services received ( $1=$ poor to $7=$ excellent), how the services contributed to their child's improvement ( $1=$ not at all to $7=a$ lot $)$, how the clinic helped them to improve management of their child $(1=$ not at all to $7=a$ $l o t$ ), if caregivers would use the clinic again if needed ( $1=$ no, definitely not to 7 = yes, definitely), current status of the child's referral concern ( $1=$ considerably worse to $7=$ greatly improved), if caregivers would recommend the clinic to others $(1=$ no, definitely not to 7 = yes, definitely), and the caregiver's confidence in managing their child's behavior in the future $(1=$ not at all confident to $7=$ very confident). The internal consistency for these seven items was $r=$ .82 .

\section{Data Analyses}

Based on the aforementioned recommendations by Swift et al. (2009), the present study evaluated a unique, two-dimensional definition of treatment completion. Treatment completers were defined as families who completed the ECBS-CBS during a 
comprehensive intake evaluation, attended at least three treatment sessions, and completed the ECBS-CBS at the third session or later for comparison purposes. The IBM SPSS Statistics for Windows(IBM Corp., 2012) program was used to conduct the statistical analyses for this study. Families who did not attend an intake and at least three treatment sessions were designated as non-completers.

Subsequently, completers and non-completers were compared on demographic variables. Descriptive statistics were computed for all study measures. Independent-group $t$-tests were used to identify any statistically significant differences at pre-test on continuous variables (e.g., child age) while chi-square tests were used to assess significant differences on categorical variables (e.g., child gender, caregiver employment status).

For research question one, treatment completers' scores on the ECBS-CBS were collected for individuals who met the minimum treatment length at each treatment session and analyzed to determine what percentage of families successfully met a reliable change criterion. A change of five points was established to meet the RCI based on a standard deviation of 4.23 and a coefficient alpha of .87 for the ECBS-CBS. Attrition rates obtained through this new definition of treatment completers were compared with attrition rates reported in the literature for similar populations.

For research questions two through four, repeated measures, MANOVA were conducted to determine if significant change was made from pre-test to follow-up on the ECBS-CBS, ECBS-PBS, PCPA, and $P B C$ Discipline and Nurturing scales. If main or interaction effects were found to be significant, post hoc univariate $F$ tests were used to determine the source of significance, and effect sizes were examined using Cohen's $d$ (Cohen, 1988).

For research question five, participant scores on the PBC Expectations scale were separated into low (score < 40), medium (score between 40 and 60), and high (score > 60) groups. Low scores at pre-test were expected to increase at post-test and follow-up, high scores were expected to decrease, and medium scores were expected to remain static. A chi-square test of pre- and post-test groups, as well as pre-test and follow-up groups was run to analyze this hypothesis. 
For research question six, the number of children who received a diagnosis at pre-test and post-test was compared to identify whether participation in the treatment program led to a decreased rate of psychiatric diagnoses in the sample. A chi-square test was used to assess for a significant difference between pre- and post-test diagnoses.

For research question seven, a repeated measures, MANOVA was conducted to determine if significant change was made from pretest to follow-up on the PCRS and GAF scales. Significant main or interaction effects were analyzed with post hoc univariate $F$ tests, and effect sizes were examined using Cohen's $d$.

Finally, scores on the seven questions from the family satisfaction scale were summed to provide an aggregate total. All participant scores were combined, and an average score, range of scores and a standard deviation were computed.

\section{Results}

Analysis of the new two-dimensional definition of treatment completion revealed that a total of 339 out of the 447 participants (75.8\%) met the criteria, resulting in a $24.2 \%$ attrition rate. A participant flow chart is shown in Figure 1. For treatment completers, the primary outcome measure was a RCI based on the ECBS-CBS scores. Of the 339 completers, 215 (63.4\%) met the five-point change during treatment. That is, caregiver report of child behavior problems decreased by at least five points on the ECBS-CBS.

Completers and non-completers were compared on demographic variables. Children with African American caregivers were more likely to drop out of treatment (28.8\%) than Latinos (19.2\%), Caucasians $(16.4 \%)$ and individuals with multiracial backgrounds $(16.7 \%)\left[\chi^{2}(3)\right.$ $=8.36, p<.05]$, and primary caregivers who were unemployed were more likely to drop out of treatment (27.7\%) than primary caregivers who were employed $(16.3 \%)\left[\chi^{2}(1)=7.76, p=.005\right]$. In addition, completers and non-completers were compared on participation measures. Completers attended an average of 8.22 sessions ( $S D=$ 3.54 ), and non-completers attended an average of 2.84 sessions ( $S D$ $=1.03)$, which represented a significant difference between groups $[t(444)=15.3, p<.001]$. Completers had an attendance rate of $81.9 \%(S D=15.4 \%)$ while non-completers had an attendance rate of

Journal of Social Service Research, Vol. 40, No. 5 (2014): pg. 623-641. DOI. This article is (c) Taylor \& Francis (Routledge) and permission has been granted for this version to appear in e-Publications@Marquette. Taylor \& Francis (Routledge) does not grant permission for this article to be further copied/distributed or hosted elsewhere without the express permission from Taylor \& Francis (Routledge). 
$61.6 \%(S D=21.4 \%)$. These attendance rates were significantly different $[t(443)=10.67, p<.001]$. Average treatment length was 2.76 months $(S D=1.42)$ for completers and 1.53 months $(S D=.76)$ for non-completers, again reflecting a significant difference between groups $[t(439)=8.45, p<.001]$. Of particular note, program completers did not differ from non-completers on any of the study's outcome measures at pre-test. Table 1 includes all comparisons between completers and non-completers.

In addition, repeated measures, MANOVA were used to analyze pre-test, post-test, and follow-up evaluations. As mentioned, many families drop out of PCT treatment due to contextual factors. As a result, of the 339 families who completed an intake and participated in at least three treatment sessions, 264 had a formal post-test evaluation. MANOVA results showed a significant time effect with large effect sizes from pre-test to follow-up on both the ECBS-CBS $[F(1.896,225.608)=76.38, p<.001$, Cohen's $d=1.61]$ and the ECBS-PBS $[F(2,238)=39.21, p<.001$, Cohen's $d=1.15]$. A significant time effect with a large effect size also was found on the PBC discipline scale $[F(1.897,221.964)=38.59, p<.001$, Cohen's $d$ $=1.15]$ while a significant time effect with a medium effect size was found on the PBC nurturing scale $[F(1.788,207.446)=5.84, p=$ .005 , Cohen's $d=.45$ ]. Results for the PCPA showed a significant time effect on the child behavior scale with a large effect size $[F(1.84$, $173.065)=23.46, p<.001$, Cohen's $d=1.0]$. For all analyses except the $\mathrm{PBC}$ nurturing scale, pairwise comparisons revealed significant differences from pre-test to post-test, and maintenance of significant differences at follow-up. On the PBC nurturing scale, significant change was found from pre-test to follow-up.

For the PBC expectations scale, a chi-squared test of pre- and post-test groups was significant $\left[\chi^{2}(4)=31.73, p<.001\right]$. Analysis of results showed that 20 of 37 participants (54\%) moved from the low to medium group while 22 of 32 participants (69\%) moved from the high to medium group. A chi-squared test of pre-test and follow-up groups also was significant $\left[\chi^{2}(4)=12.39, p<.02\right]$. Analysis of results showed that 14 of 19 participants (74\%) moved from the low to medium group while 9 of 16 participants (56\%) moved from the high to medium group. 


\section{Clinical Significance}

Of the $96.4 \%$ of children who received a primary diagnosis at intake, $39.7 \%$ met the criteria for a psychiatric diagnosis at post-test. A chi-square test revealed this change to be statistically significant $\left[\chi^{2}(100)=704.76, p<.001\right]$. A MANOVA analysis of GAF scores showed a significant time effect with a large effect size $[F(1.797$, $199.455)=265.81, p<.001$, Cohen's $d=3.09]$. There also was a significant time effect for the PCRS indicating overall improvement in the parent-child relationship with a large effect size $[F(1.806$, 204.031) $=175.84, p<.001$, Cohen's $d=2.5]$. Pairwise comparisons also revealed significant improvement from pre-test to post-test with maintenance of treatment gains at follow-up (see Table 2).

\section{Family Satisfaction}

On the FSS, scores from each of the seven items (range 1 to 7 ) were summed to create an aggregate score ranging from 7 (low satisfaction) to 49 (high satisfaction). Mean score at post-test was $43.71(S D=4.7)$ indicating a high level of satisfaction following treatment.

\section{Discussion}

The present study developed, implemented, and analyzed a new definition of treatment completion. This definition consisted of two components: (a) treatment duration and (b) a RCI for the primary outcome measure of child behavior problems. Results indicated a significantly lower attrition rate than generally reported in PCT programs for low-income families (Nicholson et al., 2002; Chaffin et al., 2009). By engaging caregivers in their home environment, PYC may have helped circumvent the typical contextual barriers for lowincome families, resulting in this decreased attrition rate. Notably, findings also showed that three sessions was an appropriate cutoff for treatment duration because the majority of participants who completed three sessions also met the RCI criterion on the ECBS-CBS. That is, the majority of participants who attended at least three sessions also achieved significant, reliable, and sustainable change on the ECBS-CBS. Of important note, program completers did not differ 
from non-completers on any of the study's outcome measures at pretest suggesting that differences may best be attributed to contextual factors as suggested by Nicholson et al. (1999), some of which included loss of phone services, financial and family crises, and frequent relocation. Alternatively, as supported by the RCI, a possible explanation for participant drop-out after the third session is that participants had received a sufficient amount of information and felt capable enough to manage their children's behavior problems independently. Thus, this new definition of treatment completion revealed significantly lowered potentially biased attrition rates compared to the current PCT research. This offered a substantial addition to the research methodology by allowing greater specificity of successful treatment completion.

The results of this study also provided additional evidence for the PYC program as a successful and effective intervention for children five years of age and younger who are referred for severe behavior and emotional problems. Children showed a significant decrease in the frequency and severity of challenging behaviors (e.g., hitting, kicking) as well as a significant increase in pro-social behaviors (e.g., sharing, listening). In addition, caregivers exhibited significant increases in the use of appropriate discipline strategies and nurturing activities with their children. Based on clinician observation, child interactions during play also improved significantly, suggesting an improvement in the parent-child relationship. For example, results indicated that children exhibited more positive affect and they showed greater initiation of play activities. The direct observation of child behavior in the family's natural environment provides compelling support for the in-home treatment format because clinicians were able to directly witness challenging behavior patterns and difficult parentchild interactions. Clinicians then were able to adapt treatment to each family's specific concerns rather than offer generic treatment strategies. The in-home structure also empowered caregivers to address their children's challenging behaviors in the most pragmatic setting possible, resulting in this study's positive outcomes. For all outcomes, improvements were maintained at four-to-six week followup, importantly highlighting the long-term efficacy of the PYC program. This long-term, sustainable impact is likely a result of the program's requirement that caregivers directly implement treatment strategies and participate fully in the intervention. By the end of 
treatment, caregivers had developed the necessary skills to manage their children's challenging behaviors independently.

This study used a novel approach to analyzing caregivers' expectations of their children. Previous PYC research has reported conflicting findings on caregivers' expectations (Nicholson et al., 1999; Nicholson et al., 2002; Fox \& Holtz, 2009). One of the suspected reasons for these results was that caregivers with high developmental expectations decreased by the end of treatment while caregivers with low developmental expectations increased, thus eliminating the significance of the effect. This new analysis procedure helped identify caregivers who had high expectations and low expectations prior to treatment, in order to determine if these caregivers adjusted their expectations to be more developmentally appropriate by the end of treatment. The analysis revealed that a significant amount of participants reported more developmentally-appropriate expectations of their children following treatment. This unique method provides a new and effective manner of analyzing caregiver expectations in future research. Overall, the study findings provide additional evidence for the success of early interventions for children with severe behavior and emotional problems while also taking the first step in developing a multi-dimensional definition of treatment completion by focusing on treatment duration and a RCI of the primary outcome measure.

Important clinical implications were noted. Almost two-thirds of participants who received a diagnosis at intake no longer had the diagnosis following treatment. This supports the clinical impact of offering early interventions to prevent the development of ingrained behavior patterns during later childhood and adolescence. Parent-child relationships also showed significant improvement, and a high level of caregiver satisfaction was reported. These findings indicate the direct effect and positive influence of the PCT program on parent-child interactions.

\section{Limitations}

Although the current research adds important information to the body of literature, the presence of a control or comparison group could strengthen the methodology. The use of a wait-list control group, while a valuable component to efficacy research, offers significant challenges and potential risks. For example, the high average attrition 
rate of $50 \%$ for children from low-income families (Nicholson et al., 1999) represents a significant problem for PCT treatment, and a waitlist control group would likely increase this attrition rate. Given the postulated contextual factors (e.g., frequent relocation, disconnection of phone line) that contribute to high attrition rates in low-SES populations, a delay would likely exacerbate the participant dropout rate.

Another limitation of this study is the relatively low reliability of the PCPA. To address this issue, the PCPA was adapted, and a new version is being used in current PYC projects. Preliminary findings of inter-rater reliability show significantly improved kappa levels. Future studies must address this limitation.

Statistical support for the new definition of treatment completion should be strengthened. Although a three-session cutoff was established based on treatment protocol, future studies should examine further statistical support of this definition. This type of analysis would either provide additional evidence for the three-session cutoff, or help identify a more appropriate cutoff for treatment completion. Further, this study lacked a third potentially important component to the multi-dimensional definition of successful treatment completion: clinician observation of caregiver participation. Clinician judgment generally has been accepted as the most preferred and accurate method of defining successful treatment completion (Pekarik, 1985; Swift et al., 2009). Therefore, clinician observation should be used for comparison to caregiver self-report of child improvement. Presently, a newly-developed measure of clinician observation is being used with the current PYC program. Preliminary results indicate good inter-rater agreement, and future studies should analyze reliability and participant outcomes on this measure. Once this measure is established, a three-dimensional approach to treatment success should include: (a) treatment duration, (b) a RCI for the primary outcome measure, and (c) clinician observation of caregiver participation in treatment.

\section{Conclusion}

This PCT program implemented several methods to address child behavior problems in at-risk children from low-income families. Treatment included non-directive child-led play, psychoeducation

Journal of Social Service Research, Vol. 40, No. 5 (2014): pg. 623-641. DOI. This article is @ Taylor \& Francis (Routledge) and permission has been granted for this version to appear in e-Publications@Marquette. Taylor \& Francis (Routledge) does not grant permission for this article to be further copied/distributed or hosted elsewhere without the express permission from Taylor \& Francis (Routledge). 
about child behavior, and cognitive-behavioral techniques to manage caregiver frustration. Appropriate discipline strategies also were implemented, such as ignoring, redirection, limit setting, natural consequences, and time-outs while all forms of verbal and corporal punishment were strongly discouraged. This study's findings highlight the efficacy of an in-home format as an effective way to reduce attrition, directly observe children in their natural environment, and help improve both child behavior and parent-child interactions. Given the relatively heterogeneous sample, this study's results support previous research on the efficacy of PYC with diverse ethnic groups (Gresl et al., in press), indicating that this PCT program can be used confidently with families from a variety of ethnic backgrounds. These successful outcomes emphasize the need for increased treatment providers in order to expand the reach of PCT programs nationwide. The significant and growing need of at-risk children with severe behavior and emotional problems demands that the field of mental health take steps to address this paucity of programs. Without early detection and intervention, challenging behaviors will likely persist and become more resistant to change later in life. While we have seen an increase in PCT programs for low-income families, these are only the initial steps to offering effective early intervention programs to at-risk children. This PCT program offers further support for the impact of early intervention PCT programs.

\section{Implications for Future Research}

Given the positive results of this PCT program, this study helps guide future PCT research toward providing highly effective early intervention services for low-income families by circumventing potential barriers to treatment. The new two-dimensional definition of treatment completion provides the foundation toward a potentially universal approach to successful treatment completion of PCT programs, which will help address the inherent challenges (e.g., attrition) in working with at-risk families living in poverty. Future research should further develop this multi-dimensional definition by incorporating a clinician observation of caregiver participation in treatment as well as establishing greater statistical support for this definition. Future studies also should attempt to implement a randomized, wait-list control group to establish the contributory effect of PCT programs on participant outcomes. This study's findings 
suggest that it is possible to change child behavior problems early in life, thus substantially affecting long-term societal outcomes for at-risk children, including peer social interactions, parent-child relationships, incidence of child abuse, and academic success; the next step is to build on these initial findings.

\section{References}

1. Abidin, R. R., Jenkins, C. L., \& McGaughey, M. C. (1992). The relationship of early family variables to children's subsequent behavioral adjustment. Journal of Clinical Child Psychology, 21(1), 60-69.

2. Ackerman, B. P., Brown, E., \& Izard, C. E. (2003). Continuity and change in levels of externalizing behavior in school of children from economically disadvantaged families. Child Development, 74, 694-709.

3. Anthony, B. J., Anthony, L. G., Morrel, T. M., \& Acosta, M. (2005). Evidence for social and behavior problems in low-income, urban preschoolers: Effects of site, classroom, and teacher. Journal of Youth and Adolescence, 34, 31-39.

4. Ateah, C. A., \& Durrant, J. E. (2005). Maternal use of physical punishment in response to child misbehavior: Implications for child abuse prevention. Child Abuse \& Neglect, 29, 169-185.

5. Barkham, M., Connell, J., Stiles, W. B., Miles, J. N. V., Margison, F., Evans, C., \& Mellor-Clark, J. (2006). Dose-effect relations and responsive regulation of treatment duration: The good enough level. Journal of Consulting and Clinical Psychology, 74(1), 160-167.

6. Barth, R. P., Greeson, J. K. P., Guo, S., Green, R. L., Hurley, S., \& Sisson, J. (2007). Outcomes for youth receiving intensive in-home therapy or residential care: A comparison using propensity scores. American Journal of Orthopsychiatry, 77(4), 497-505. doi: http://dx.doi.org/10.1037/0002-9432.77.4.497

7. Breitenstein, S. M., Gross, D., Ordaz, I., Julion, W., Garvey, C., \& Ridge, A. (2007). Promoting mental health in early childhood programs serving families from low-income neighborhoods. Journal of the American Psychiatric Nurses Association, 13(5), 313-320.

8. Brenner, V., \& Fox, R. A. (1998). Parental discipline and behavior problems in young children. Journal of Genetic Psychology, 159(2), 251-256.

Journal of Social Service Research, Vol. 40, No. 5 (2014): pg. 623-641. DOI. This article is (c) Taylor \& Francis (Routledge) and permission has been granted for this version to appear in e-Publications@Marquette. Taylor \& Francis (Routledge) does not grant permission for this article to be further copied/distributed or hosted elsewhere without the express permission from Taylor \& Francis (Routledge). 
9. Brotman, L. M., Calzada, E., Huang, K., Kingston, S., Dawson-McClure, S., Kamboukos, D., ...Petkova, E. (2011). Promoting effective parenting practices and preventing child behavior problems in school among ethnically diverse families from underserved, urban communities. Child Development, 82(1), 258-276.

10. Bulotsky-Shearer, R. J., Dominquez, X., \& Bell, E. R. (2012). Preschool classroom behavioral context and school readiness outcomes for lowincome children: A multilevel examination of child- and classroomlevel influences. Journal of Educational Psychology, 104(2), 421-438.

11. Campbell, S. B. (1995). Behavior problems in preschool children: A review of recent research. Journal of Child Psychology \& Psychiatry, 36, 113149.

12. Campbell, S. B. (2002). Behavior problems in preschool children: Clinical and developmental issues (2nd ed.). New York: Guilford.

13. Carrasco, J., \& Fox, R. A., (2012). Varying treatment intensity in a homebased parent and child therapy program for families living in poverty: A randomized clinical trial. Journal of Community Psychology, 40(5), 621-630.

14. Chaffin, M., Valle, L. A., Funderbunk, B., Gurwitch, R., Silovsky, J., Bard, D., ...Kees, M. (2009). A motivational intervention can improve retention in PCIT for low-motivation child welfare clients. Child Maltreatment, 14, 356-368.

15. Coard, S. I., Wallace, S. A., Stevenson, H. C., \& Brotman, L. M. (2004). Towards culturally relevant preventive interventions: The consideration of racial socialization in parent training with African American families. Journal of Child and Family Studies, 13, 277-293.

16. Cohen, J. (1988). Statistical power analysis for the behavioral sciences ( ${ }^{\text {nd }}$ edition). Hillsdale, NJ: Erlbaum.

17. Crawley, S. B., \& Spiker, D. (1983). Mother-child interactions involving two-year-olds with Down syndrome: A look at individual differences. Child Development, 54, 1312-1323. 
18. de Graaf, I., Speetjens, P., Smit, F., de Wolff, M., \& Tavecchio, L. (2008). Effectiveness of the Triple $P$ Positive Parenting Program on parenting: A meta-analysis. Family Relations, 57, 553-566.

19. Einfeld, S. L., Piccinin, A. M., Mackinnon, A., Hofer, S. M., Taffe, J., Gray, K. M., ...Tonge, B. J. (2006). Psychopathology in young people with intellectual disabilities. Journal of Intellectual Disability Research, 47, 51-58.

20. Eyberg, S. M., \& Boggs, S. R. (1989). Parent training for oppositionaldefiant preschoolers. In C. E. Schaefer \& J. M. Briesmeister (Eds.), Handbook of parent training: Parents as co-therapists for children's behavior problems (pp. 105-132). New York: Wiley.

21. Eyberg, S. M., Funderburk, B. W., Hembree-Kigin, T. L., McNeil, C. B., Querido, J. G., \& Hood, K. K. (2001). Parent-Child Interaction Therapy with behavior problem children: One and two year maintenance of treatment effects in the family. Child \& Family Behavior Therapy, 23(4), 1-20.

22. Eyberg, S. M., \& Pincus, D. (1999). Eyberg Child Behavior Inventory and Sutter-Eyberg Student Behavior Inventory-Revised: Professional manual. Lutz, Florida: Psychological Assessment Resources, Inc.

23. Fernandez, M. A., Butler, A. M., \& Eyberg, S. M. (2011). Treatment outcome for low socioeconomic status African American families in Parent-Child Interaction Therapy: A pilot study. Child \& Family Behavior Therapy, 33, 32-48.

24. Fox, R. A. (1994). Parent behavior checklist. Austin, TX: ProEd (Currently available from the author, Marquette University, School of Education, P.O. Box 1881, Milwaukee, WI 53201-1881; Email: robert.fox@marquette.edu).

25. Fox, R. A. (2013). Behavior Clinic: Treatment and training manual. (Currently available from the author, Marquette University, School of Education, P.O. Box 1881, Milwaukee, WI 53201-1881; Email: robert.fox@marquette.edu).

26. Fox, R. A., \& Fox, T. A. (1992). Leader's guide: STAR parenting program. Bellevue, WA: STAR Parenting, Inc.

Journal of Social Service Research, Vol. 40, No. 5 (2014): pg. 623-641. DOI. This article is @ Taylor \& Francis (Routledge) and permission has been granted for this version to appear in e-Publications@Marquette. Taylor \& Francis (Routledge) does not grant permission for this article to be further copied/distributed or hosted elsewhere without the express permission from Taylor \& Francis (Routledge). 
NOT THE PUBLISHED VERSION; this is the author's final, peer-reviewed manuscript. The published version may be accessed by following the link in the citation at the bottom of the page.

27. Fox, R. A., \& Holtz, C. A. (2009). Treatment outcomes for toddlers with behaviour problems from families in poverty. Child and Adolescent Mental Health, 14(4), 183-189.

28. Fox, R. A., Keller, K. M., Grede, P. L., \& Bartosz, A. M. (2007). A mental health clinic for toddlers with developmental delays and behavior problems. Research in Developmental Disabilities, 28, 119-129.

29. Fox, R. A., \& Nicholson, B. C. (2003). Parenting young children: A facilitator's guide. Longmont, $\mathrm{CO}$ : Sopris West.

30. Fox, R. A., Platz, D. L., \& Bentley, K. S. (1995). Maternal factors related to parenting practices, developmental expectations, and perceptions of child behavior problems. The Journal of Genetic Psychology, 156(4), 431-441.

31. Francis, K. J., \& Wolfe, D. A. (2008). Cognitive and emotional differences between abusive and non-abusive fathers. Child Abuse \& Neglect, 32, 1127-1137.

32. Greene, R. W., \& Doyle, A. E. (1999). Toward a transactional conceptualization of oppositional defiant disorder: Implications for assessment and treatment. Clinical Child and Family Psychology Review, 2, 129-148.

33. Gresl, B. L., Fox, R. A., \& Fleischmann, A. (in press). Home-based parentchild therapy in low-income African American, Caucasian, and Latino families: A comparative examination of treatment outcomes. Child \& Family Behavior Therapy.

34. Gross, D., Garvey, C., Julion, W., Fogg, L., Tucker, S., \& Mokros, H. (2009). Efficacy of the Chicago Parent Program with low-income African American and Latino parents of young children. Prevention Science, 10, 54-65.

35. Hatchett, G. T., \& Park, H. L. (2003). Comparison of four operational definitions of premature termination. Psychotherapy: Theory, Research, Practice, Training, 40, 226-231.

36. Holtz, C. A., Carrasco, J. M., Mattek, R. J., \& Fox, R. A. (2009). Behavior problems in toddlers with and without developmental delays:

Journal of Social Service Research, Vol. 40, No. 5 (2014): pg. 623-641. DOI. This article is @ Taylor \& Francis (Routledge) and permission has been granted for this version to appear in e-Publications@Marquette. Taylor \& Francis (Routledge) does not grant permission for this article to be further copied/distributed or hosted elsewhere without the express permission from Taylor \& Francis (Routledge). 
NOT THE PUBLISHED VERSION; this is the author's final, peer-reviewed manuscript. The published version may be accessed by following the link in the citation at the bottom of the page.

Comparison of treatment outcomes. Child \& Family Behavior Therapy, 31, 292-311.

37. Holtz, C. A., \& Fox, R. A. (2012). Behavior problems in young children from low-income families: The development of a new screening tool. Infant Mental Health Journal, 33(1), 82-94.

38. IBM Corp. (2012). IBM SPSS Statistics for Windows, Version 21.0. Armonk, NY: IBM Corp.

39. Jacobson, N. S., \& Truax, P. (1991). Clinical significance: A statistical approach to defining meaningful change in psychotherapy research. Journal of Consulting and Clinical Psychology, 59, 12-19.

40. Kazdin, A. E., \& Mazurick, J. L. (1994). Dropping out of child psychotherapy: Distinguishing early and late dropouts over the course of treatment. Journal of Consulting and Clinical Psychology, 62(5), 1069-1074

41. Kazdin, A. E., \& Whitley, M. K. (2003). Treatment of parental stress to enhance therapeutic change among children referred for aggressive and antisocial behavior. Journal of Consulting and Clinical Psychology, 71(3), 504-515.

42. Keenan, K. Shaw, D., Delliquadri, E., Giovannelli, J., \& Walsh, B. (1998). Evidence for the continuity of early problem behaviors: Application of a developmental model. Journal of Abnormal Child Psychology, 26(6), 441-454.

43. Keenan, K., \& Wakschlag, L. (2000). More than the terrible twos: The nature and severity of behavior problems in clinic-referred preschool children. Journal of Abnormal Child Psychology, 28, 33-46.

44. Lavigne, J. V., LeBailly, S. A., Gouze, K. R., Binns, H. J., Keller, J., \& Pate, L. (2010). Predictors and correlates of completing behavioral parent training for the treatment of oppositional defiant disorder in pediatric primary care. Behavior Therapy, 41, 198-211.

45. Longo, D. A., Lent, R. W., \& Brown, S. D. (1992). Social cognitive variables in the prediction of client motivation and attrition. Journal of Counseling Psychology, 39, 447-452.

Journal of Social Service Research, Vol. 40, No. 5 (2014): pg. 623-641. DOI. This article is @ Taylor \& Francis (Routledge) and permission has been granted for this version to appear in e-Publications@Marquette. Taylor \& Francis (Routledge) does not grant permission for this article to be further copied/distributed or hosted elsewhere without the express permission from Taylor \& Francis (Routledge). 
NOT THE PUBLISHED VERSION; this is the author's final, peer-reviewed manuscript. The published version may be accessed by following the link in the citation at the bottom of the page.

46. Lyon, A. R., \& Budd, K. S. (2010). A community mental health implementation of Parent-Child Interaction Therapy (PCIT). Journal of Child and Family Studies, 19, 654-668. doi: 10.1007/s10826-0109353-z

47. Mendez, J. L., Fantuzzo, J., \& Cicchetti, D. (2002). Profiles of social competence among low-income African American preschool children. Child Development, 73, 1085-1101.

48. Moffitt, T. E. (2005). The new look of behavioral genetics in developmental psychopathology: Gene-environment interplay in antisocial behaviors. Psychological Bulletin, 131(4), 533-554. doi:http://dx.doi.org/10.1037/0033-2909.131.4.533

49. Nicholson, B., Anderson, M., Fox, R., \& Brenner, V. (2002). One family at a time: A prevention program for at-risk parents. Journal of Counseling \& Development, 80, 362-371.

50. Nicholson, B. C., Brenner, V., \& Fox, R. A. (1999). A community-based parenting program with low-income mothers of young children. Families in Society, 80(3), 247-253.

51. Nicholson, B. C., Fox, R. A., \& Johnson S. D. (2005). Parenting young children with challenging behaviour. Infant and Child Development, 14, 425-428.

52. Patterson, G. R., \& Forgatch, M. S. (1990). Initiation and maintenance of process disrupting single-mother families. In G. R. Patterson (Ed.), Depression and aggression in family interaction (pp. 209-245). Hillsdale, NJ: Erlbaum.

53. Patterson, G. R., Reid, J. B., \& Dishion, T. J. (1992). Antisocial boys. Eugene, OR: Castalia.

54. Qi, C. H., \& Kaiser, A. P. (2003). Behavior problems of preschool children from low-income families: Review of the literature. Topics in Early Childhood Special Education, 23(4), 188-216.

Journal of Social Service Research, Vol. 40, No. 5 (2014): pg. 623-641. DOI. This article is @ Taylor \& Francis (Routledge) and permission has been granted for this version to appear in e-Publications@Marquette. Taylor \& Francis (Routledge) does not grant permission for this article to be further copied/distributed or hosted elsewhere without the express permission from Taylor \& Francis (Routledge). 
NOT THE PUBLISHED VERSION; this is the author's final, peer-reviewed manuscript. The published version may be accessed by following the link in the citation at the bottom of the page.

55. Reid, M. J., Webster-Stratton, C., \& Baydar, N. (2004). Halting the development of conduct problems in Head Start children: The effects of parent training. Journal of Clinical Child and Adolescent Psychology, $33(2), 279-291$.

56. Roberts, C., Mazzucchelli, T., Studman, L., \& Sanders, M. R. (2006). Behavioral family intervention for children with developmental disabilities and behavioral problems. Journal of Clinical and Adolescent Psychology, 35, 180-193.

57. Sanders, M. R. (1999). Triple P-Positive parenting program: Towards an empirically validated multilevel parenting and family support strategy for the prevention of behavior and emotional problems in children. Clinical Child and Family Psychology Review, 2, 71-90.

58. Sanders, M. R., Dadds, M. R., \& Bor, W. (1989). Contextual analysis of child oppositional and maternal aversive behaviors in families of conduct-disordered and nonproblem children. Journal of Clinical Child Psychology, 18, 72-83.

59. Sanders, M. R., Dadds, M. R., Johnston, B. M., \& Cash, R. (1992). Childhood depression and conduct disorder: I. Behavior, affective, and cognitive aspects of family problem-solving interactions. Journal of Abnormal Psychology, 101(3), 495-504.

60. Shaw, D. S., Lacourse, E., \& Nagin, D. S. (2005). Developmental trajectories of conduct problems and hyperactivity from ages 2 to 10 . Journal of Child Psychology \& Psychiatry, 46, 931-942.

61. Snarr, J. D., Smith Slep, A. M., \& Grande, V. P. (2009). Validation of a new self-report measure of parental attribution. Psychological Assessment, $21,390-401$.

62. Spencer, M. S., Kohn, L. P., \& Woods, J. R. (2002). Labeling vs. early identification: The dilemma of mental health service utilization among low-income African American children. African American Research Perspectives, 8, 1-14.

Journal of Social Service Research, Vol. 40, No. 5 (2014): pg. 623-641. DOI. This article is (C) Taylor \& Francis (Routledge) and permission has been granted for this version to appear in e-Publications@Marquette. Taylor \& Francis (Routledge) does not grant permission for this article to be further copied/distributed or hosted elsewhere without the express permission from Taylor \& Francis (Routledge). 
NOT THE PUBLISHED VERSION; this is the author's final, peer-reviewed manuscript. The published version may be accessed by following the link in the citation at the bottom of the page.

63. Strassberg, Z. (1995). Social information processing in compliance situations by mothers of behavior-problem boys. Child Development, 66, 376-389.

64. Swift, J. K., Callahan, J., \& Levine, J. C. (2009). Using clinically significant change to identify premature termination. Psychotherapy: Theory, Research, Practice, Training, 46(3), 328-335. doi: 10.1037/a0017003

65. Viera, A. J., \& Garrett, J. M. (2005). Understanding interobserver agreement: The Kappa statistic. Research Series, 37(5), 360-363.

66. Webster-Stratton, C. (1992). The Incredible Years: A trouble shooting guide for parents of children age 3-8 years. Toronto: Umbrella Press.

67. Webster-Stratton, C., Reid, M. J., \& Hammond, M. (2004). Treating children with early-onset conduct problems: Intervention outcomes for parent, child, and teacher training. Journal of Clinical Child and Adolescent Psychology, 33(1), 105-124.

68. Webster-Stratton, C., Reid, M. J., \& Stoolmiller, M. (2008). Preventing conduct problems and improving school readiness: Evaluation of the Incredible Years Teacher and Child Training Programs in high-risk schools. The Journal of Child Psychology and Psychiatry, 49(5), 471488.

69. Wierzbicki, M., \& Pekarik, G. (1993). A meta-analysis of psychotherapy dropout. Professional Psychology: Research and Practice, 24(2), 190195. doi: http://dx.doi.org/10.1037/0735-7028.24.2.190

70. Wood, S., Barton, K., \& Schroeder, C. (1988). In-home treatment of abusive families: Cost and placement at one year. Psychotherapy: Theory, Research, Practice, Training, 25(3), 409-414. doi: http://dx.doi.org/10.1037/h0085362

71. Youngstrom, E., Weist, M. D., \& Albus, K. E. (2003). Exploring violence exposure, stress, protective factors and behavioral problems among inner-city youth. American Journal of Community Psychology, 32, 115129.

Journal of Social Service Research, Vol. 40, No. 5 (2014): pg. 623-641. DOI. This article is @ Taylor \& Francis (Routledge) and permission has been granted for this version to appear in e-Publications@Marquette. Taylor \& Francis (Routledge) does not grant permission for this article to be further copied/distributed or hosted elsewhere without the express permission from Taylor \& Francis (Routledge). 
NOT THE PUBLISHED VERSION; this is the author's final, peer-reviewed manuscript. The published version may be accessed by following the link in the citation at the bottom of the page.

Table 1: Comparison of Treatment Completers and Non-completers at Pre-test

\begin{tabular}{|c|c|c|c|c|c|c|c|c|}
\hline \multirow[b]{2}{*}{ Variable } & \multicolumn{4}{|c|}{ Completers } & \multicolumn{4}{|c|}{ Non-Completers } \\
\hline & $M$ & $S D$ & $n$ & $\%$ & $M$ & $S D$ & $n$ & $\%$ \\
\hline Age of Child & 3.17 & 1.08 & 339 & 100 & 3.12 & .97 & 108 & 100 \\
\hline \multicolumn{9}{|l|}{ Gender } \\
\hline Female & & & 109 & 32 & & & 38 & 35 \\
\hline Male & & & 230 & 68 & & & 70 & 65 \\
\hline \multicolumn{9}{|l|}{ Race } \\
\hline African American & & & 167 & $49 *$ & & & 68 & $63^{* *}$ \\
\hline Latino & & & 73 & 22 & & & 16 & 15 \\
\hline Caucasian & & & 41 & 12 & & & 8 & 7 \\
\hline Mixed Ethnicity & & & 58 & 17 & & & 16 & 15 \\
\hline Psychiatric Diagnosis & & & 324 & 96 & & & 100 & 97 \\
\hline Developmental Delay & & & 152 & 45 & & & 21 & 19 \\
\hline \multicolumn{9}{|l|}{ Primary Caretaker } \\
\hline Mother & & & 302 & 89 & & & 96 & 89 \\
\hline Other & & & 37 & 11 & & & 12 & 11 \\
\hline Public Assistance & & & 299 & 88 & & & 98 & 91 \\
\hline $\begin{array}{l}\text { Primary Caretaker Drug/Alcohol } \\
\text { Use During Pregnancy }\end{array}$ & & & 49 & 14 & & & 16 & 15 \\
\hline $\begin{array}{l}\text { Pregnancy or Delivery } \\
\text { Complications }\end{array}$ & & & 120 & 35 & & & 38 & 35 \\
\hline Significant Past Health Concerns & & & 178 & 53 & & & 48 & 44 \\
\hline Primary Caretaker Employed & & & 144 & 42 & & & 28 & 26 \\
\hline Age of Primary Caretaker & 30.05 & 8.50 & & & 28.63 & 7.39 & & \\
\hline Birthweight (in pounds) & 6.67 & 1.84 & & & 6.77 & 1.51 & & \\
\hline
\end{tabular}

Journal of Social Service Research, Vol. 40, No. 5 (2014): pg. 623-641. DOI. This article is (c) Taylor \& Francis (Routledge) and permission has been granted for this version to appear in e-Publications@Marquette. Taylor \& Francis (Routledge) does not grant permission for this article to be further copied/distributed or hosted elsewhere without the express permission from Taylor \& Francis (Routledge). 
NOT THE PUBLISHED VERSION; this is the author's final, peer-reviewed manuscript. The published version may be accessed by following the link in the citation at the bottom of the page.

Table 1: Continued

\begin{tabular}{|c|c|c|c|c|c|c|c|c|}
\hline \multicolumn{9}{|l|}{ ECBS } \\
\hline Pro-social & 22.02 & 3.14 & & & 22.36 & 3.36 & & \\
\hline Challenging & 22.78 & 4.14 & & & 23.31 & 4.52 & & \\
\hline \multicolumn{9}{|l|}{ PBC } \\
\hline Discipline & 14.96 & 4.29 & & & 15.02 & 3.95 & & \\
\hline Nurturing & 29.37 & 5.63 & & & 29.14 & 5.41 & & \\
\hline Expectations (low/high groups) & & & 101 & 30 & & & 36 & 33 \\
\hline \multicolumn{8}{|l|}{ PCPA } & \\
\hline Child & 14.24 & 3.42 & & & 13.69 & 3.81 & & \\
\hline Parent & 15.01 & 4.14 & & & 14.51 & 3.90 & & \\
\hline PCRS & 50.62 & 13.90 & & & 47.12 & 15.54 & & \\
\hline GAF & 52.47 & 8.49 & & & 52.69 & 8.37 & & \\
\hline $\begin{array}{l}\text { Number of Sessions Attended, } \\
\text { Including Intake }\end{array}$ & $8.22 * * *$ & 3.54 & & & 2.84 & 1.03 & & \\
\hline \multicolumn{8}{|l|}{ Time in Treatment (in months) } & \\
\hline \multirow[t]{2}{*}{ Session Attendance Rate (\%) } & $1.53 * * *$ & .76 & & & 2.76 & 1.42 & & \\
\hline & $81.85^{* * *}$ & 15.38 & & & 61.58 & 21.36 & & \\
\hline
\end{tabular}

Note: $* \mathrm{p}<.05 . * * \mathrm{p}<.01 . * * * \mathrm{p}<.001$.

Journal of Social Service Research, Vol. 40, No. 5 (2014): pg. 623-641. DOI. This article is (C) Taylor \& Francis (Routledge) and permission has been granted for this version to appear in e-Publications@Marquette. Taylor \& Francis (Routledge) does not grant permission for this article to be further copied/distributed or hosted elsewhere without the express permission from Taylor \& Francis (Routledge). 
NOT THE PUBLISHED VERSION; this is the author's final, peer-reviewed manuscript. The published version may be accessed by following the link in the citation at the bottom of the page.

Table 2 Repeated Measures MANOVA for Children Completing Treatment at Pretest, Post-test, and Follow-up

\begin{tabular}{|c|c|c|c|c|c|c|c|}
\hline \multirow[b]{2}{*}{ Measures } & \multicolumn{2}{|c|}{ Pre-test } & \multicolumn{3}{|l|}{ Post-test } & \multicolumn{2}{|c|}{ Short-Term Follow-up } \\
\hline & $M$ & $S D$ & $M$ & $S D$ & $d^{l}$ & $S D$ & $d^{2}$ \\
\hline \multicolumn{8}{|l|}{ ECBS } \\
\hline Pro-social & 22.37 & 3.06 & $24.56^{* * *}$ & * 3.10 & 0.71 & $24.67 * * * 3.31$ & 0.72 \\
\hline Challenging & 21.79 & 4.18 & $17.44 * * *$ & * 4.16 & 1.04 & $17.70 * * * 4.45$ & 0.95 \\
\hline \multicolumn{8}{|l|}{ PCPA } \\
\hline Child & 14.46 & 3.12 & $16.89 * * *$ & * 2.80 & 0.82 & $16.65 * * * 2.95$ & 0.72 \\
\hline \multicolumn{8}{|l|}{ PBC } \\
\hline Discipline & 14.80 & 4.15 & $12.68 * * *$ & * 2.80 & 0.60 & $12.51 * * * 2.71$ & 0.65 \\
\hline Nurturing & 28.99 & 6.03 & 29.95 & 5.34 & 0.17 & $30.57^{*} \quad 5.56$ & 0.27 \\
\hline $\begin{array}{l}\text { Expectations } \\
\text { (low/high groups) }\end{array}$ & \multicolumn{2}{|c|}{69 families } & \multicolumn{3}{|c|}{27 families $* * *$} & \multicolumn{2}{|l|}{12 families** } \\
\hline GAF & 53.96 & 8.45 & $69.81^{* * *}$ & * 9.63 & 1.75 & $71.14 * * * 10.41$ & 1.81 \\
\hline PCRS & 52.41 & 13.34 & $72.72 * * *$ & *12.52 & 1.57 & $72.32 * * * 13.83$ & 0.62 \\
\hline
\end{tabular}

Note: ${ }^{*} p<.05, * * p<.01, * * * p<.001$. The notation $d^{1}$ refers to intake to post-test effect size. The notation $d^{2}$ refers to the short-term follow-up effect size.

Journal of Social Service Research, Vol. 40, No. 5 (2014): pg. 623-641. DOI. This article is (c) Taylor \& Francis (Routledge) and permission has been granted for this version to appear in e-Publications@Marquette. Taylor \& Francis (Routledge) does not grant permission for this article to be further copied/distributed or hosted elsewhere without the express permission from Taylor \& Francis (Routledge). 
NOT THE PUBLISHED VERSION; this is the author's final, peer-reviewed manuscript. The published version may be accessed by following the link in the citation at the bottom of the page.

Figure 1: Participant Flowchart from Intake through Short-Term Follow-Up Evaluations

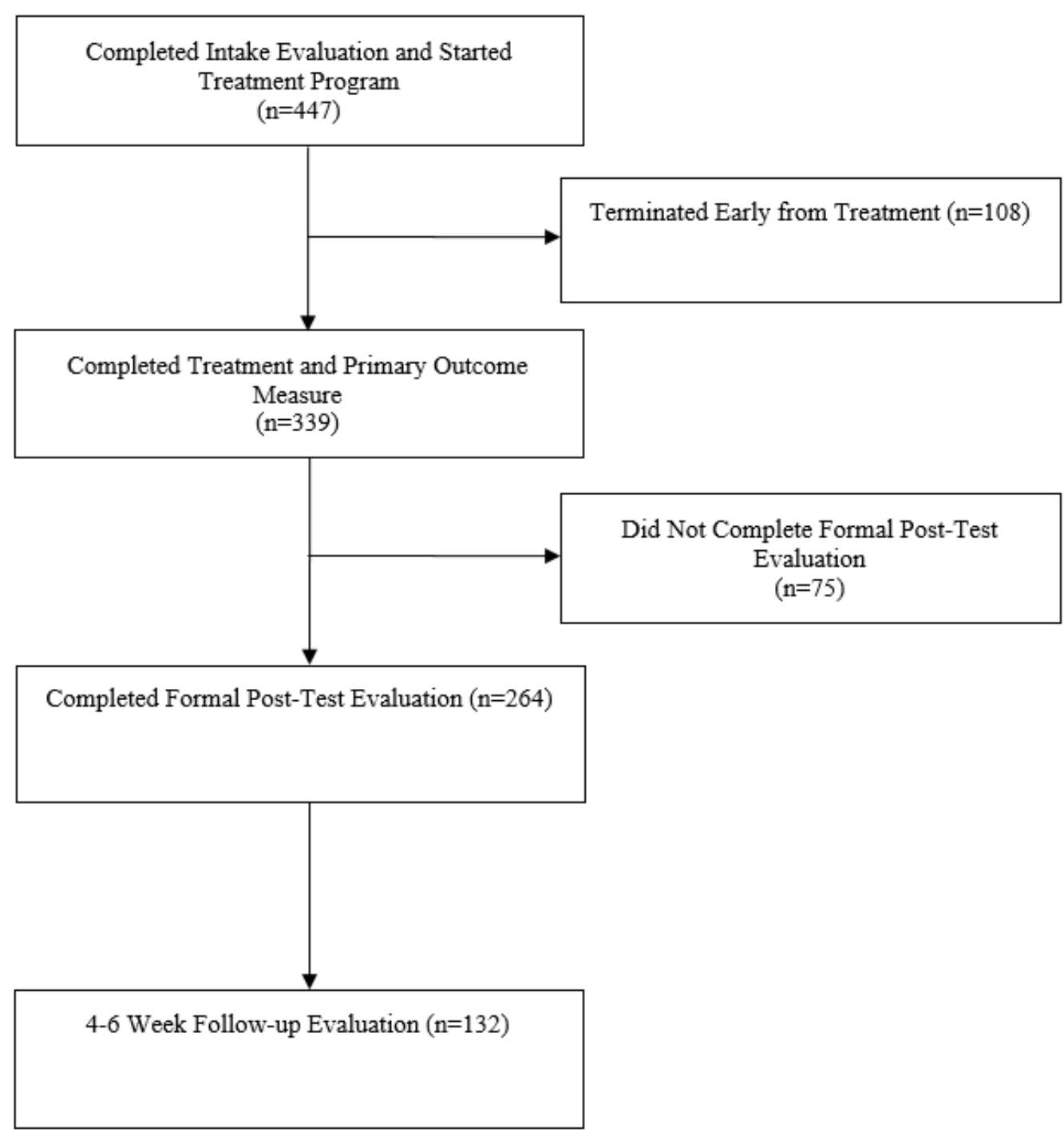

Journal of Social Service Research, Vol. 40, No. 5 (2014): pg. 623-641. DOI. This article is () Taylor \& Francis (Routledge) and permission has been granted for this version to appear in e-Publications@Marquette. Taylor \& Francis (Routledge) does not grant permission for this article to be further copied/distributed or hosted elsewhere without the express permission from Taylor \& Francis (Routledge). 